\title{
Monitoring Enzyme Reaction and Screening of Inhibitors of Acetylcholinesterase by Quantitative Matrix-Assisted Laser Desorption/ Ionization Fourier Transform Mass Spectrometry
}

\author{
Zhe Xu, Shengjun Yao, Yuanlong Wei, Jing Zhou, Li Zhang, \\ Cuihong Wang, and Yinlong Guo \\ Shanghai Mass Spectrometry Center, Shanghai Institute of Organic Chemistry, Chinese Academy of Science, \\ Shanghai, China
}

\begin{abstract}
A matrix-assisted laser desorption/ionization Fourier transform mass spectrometry (MALDIFTMS)-based assay was developed for kinetic measurements and inhibitor screening of acetylcholinesterase. Here, FTMS coupled to MALDI was applied to quantitative analysis of choline using the ratio of choline/acetylcholine without the use of additional internal standard, which simplified the experiment. The Michaelis constant $\left(K_{\mathrm{m}}\right)$ of acetylcholinesterase (AChE) was determined to be $73.9 \mu \mathrm{mol} \mathrm{L}^{-1}$ by this approach. For Huperzine A, the linear mixed inhibition of AChE reflected the presence of competitive and noncompetitive components. The half maximal inhibitory concentration $\left(\mathrm{IC}_{50}\right)$ value of galantamine obtained for AChE was $2.39 \mu \mathrm{mol} \mathrm{L}^{-1}$. Inhibitory potentials of Rhizoma Coptidis extracts were identified with the present method. In light of the results the referred extracts as a whole showed inhibitory action against AChE. The use of high-resolution FTMS largely eliminated the interference with the determination of $\mathrm{ACh}$ and $\mathrm{Ch}$, produced by the low-mass compounds of chemical libraries for inhibitor screening. The excellent correlation with the reported kinetic parameters confirms that the MS-based assay is both accurate and precise for determining kinetic constants and for identifying enzyme inhibitors. The obvious advantages were demonstrated for quantitative analysis and also high-throughput characterization. This study offers a perspective into the utility of MALDI-FTMS as an alternate quantitative tool for inhibitor screening of AChE. (J Am Soc Mass Spectrom 2008, 19, 1849-1855) (C) 2008 Published by Elsevier Inc. on behalf of American Society for Mass Spectrometry
\end{abstract}

$\mathrm{E}$ nzymatic conversions play a crucial role in the regulation of all processes of life [1]. Enzymes are an important class of targets for treatment of various diseases, such as cancer, diabetes, AIDs, and hypertension [2-4]. Because of the potential use of enzyme inhibitors as therapeutic agents, there is a general interest in development of screening procedures to identify novel enzyme inhibitors [5]. Acetylcholinesterase (AChE) rapidly catalyzes the transformation of the active neurotransmitter acetylcholine (ACh) into the inactive compounds choline $(\mathrm{Ch})$ and acetic acid (Scheme 1). Inhibition of acetylcholinesterase is considered a promising strategy for the treatment of neurological disorders such as Alzheimer's disease $(\mathrm{AD})$, senile dementia, ataxia, and myasthenia gravis $[6,7]$.

The classical approaches for screening potential inhibitors are frequently based on UV-Vis absorbance, fluorescence spectroscopy, or radioactivity detection

Address reprint requests to Dr. Yinlong Guo, Chinese Academy of Science, Shanghai Mass Spectrometry Center, Shanghai Institute of Organic Chemistry, Shanghai 200032, China. E-mail: ylguo@mail.sioc.ac.cn
[8-10]. The traditional spectrometric method for assaying AChE activity was developed by Ellman and coworkers [11]. This method was in an indirect manner that the surrogate substrate acetylthiocholine and Ellman's reagent should be used. In recent years, mass spectrometry (MS)-based assays have attracted great attention for high-throughput screening. MS offers the significant advantage that it does not require analytes to be labeled, either by direct attachment of fluorescent and radioactive labels or by binding of antibodies, and therefore offers greater flexibility in experiments [1214]. In the past decade, considerable effort was invested to develop MS-based detection schemes capable of assaying inhibition of enzyme-mediated reactions [15, 16]. The use of electrospray ionization (ESI)-MS is rapidly expanding into the study of enzyme kinetics [17-23]. Also, combinations of chromatographic and electrophoretic separation methods with ESI-MS, such as liquid chromatography (LC)/MS [24], LC/tandem mass spectroscopy (MS/MS) [25], gas chromatography (GC)/MS [26], frontal affinity chromatography (FAC)/MS [27], or capillary electrophoresis (CE)/MS [28] have been reported for the determination of acetylcholine 



Scheme 1. Acetylcholinesterase converts acetylcholine into choline and acetic acid.

or the screening of AChE inhibitors. These methods are quite specific but have longer cycle times. Some strategies based on immobilization enzyme have been used for screening of enzyme inhibitors. Because of the low dissociation rates of some inhibitors, however, it is difficult to achieve high-throughput screening $[29,30]$.

Recently, because of its high speed, low sample consumption, and high sensitivity, quantitative matrixassisted laser desorption/ionization (MALDI)-MS has been widely developed in most fields of life science for high-mass biomolecules. It is now also applied as a tool for the quantification of low molecular weight compounds of biological interest. Assaying enzyme-inhibition reactions has also been shown using matrix-free laser desorption/ionization process on porous silicon (DIOS) [31, 32] and MALDI-MS using a matrix of oxidized carbon nanotubes [33]. Fourier transform mass spectrometry (FTMS) was introduced to couple with MALDI because of its remarkable mass resolution and accuracy. Compared to other mass spectrometers, the use of FTMS as the detection system allows the production of highly accurate mass spectra of target compounds. Accurate mass determination and elemental composition data calculated thereby can be used for structure elucidation. Large amounts of compounds and/or complex plant extracts could be used for the inhibitor screening against a given target. The compounds with molecular weights in the region of enzyme substrate and product $(\mathrm{m} / \mathrm{z}<200$, in this work) would interfere with monitoring the enzymatic reaction; however, the high resolving powers of FTMS enable us to detect compounds that are close in mass/charge value. These advantages extend the MS-based inhibitor screening to natural extracts, without the need of sample purification step before MS analysis.

The present investigation focused on the quantification of the product of enzymatic reaction using substrate as internal standard, thus eliminating the need for addition of an internal standard. Herein we demonstrate the applicability of a MALDI-FTMS-based assay in the kinetics study and inhibitor screening of acetylcholinesterase. We also apply the methodology to three drugs targeting the acetylcholinesterase, including Reminyl (galantamine hydrobromide), Excelon (rivastigmine tartrate), and Huperzine A. Then, we evaluate the effect of Rhizoma Coptidis extracts on the activity of AChE.

\section{Experimental}

Reagents

All chemical reagents were obtained from commercial suppliers and used without further purification. Acetylcholinesterase from Electrophorus electricus (type VI-S, EC 3.1.1.7, AChE), acetylcholine chloride, choline chloride, $\alpha$-cyano-4-hydroxycinnamic acid (CHCA), and 2,5-dihydroxybenzoic acid (DHB) were purchased from Sigma Chemical Co. (St. Louis, MO, USA). Two AChE inhibitors, galantamine hydrobromide and Huperzine A, were provided by Kangjiu Chemical Co. (Shanghai, China). Rivastigmine tartrate was kindly provided by Prof. Xingxiang $\mathrm{Xu}$ of Shanghai Institute of Organic Chemistry (Chinese Academy of Sciences, Shanghai). Rhizoma Coptidis was purchased from Shanghai TongHan-Chun-Tang Chinese Pharmacy (China). The deionized water used in this study was from a Milli-Q water purification system (Millipore Corp.; Bedford, MA, USA). Acetonitrile and methanol were of HPLC-grade quality purchased from Merck (Darmstadt, Germany). PEG-200, PEG-400, acetone, dimethyl sulfoxide (DMSO), and ethanol were bought from Shanghai Chemical Reagent Corporation.

\section{Sample Preparation}

Sample solutions were prepared with $10 \mathrm{mM}$ Tris-HCl buffer ( $\mathrm{pH} 7.5)$, except if indicated otherwise. The matrix solution was prepared fresh daily by adding 150 $\mathrm{mg}$ of DHB to $1 \mathrm{~mL}$ of a methanol/water solution (50/50, vol/vol). PEG-200 and PEG-400 were used as external standards of mass calibration. The PEG-200 and PEG-400 solutions were prepared before experiment in the mixture of water/methanol (50/50, vol/ vol) to the concentration of $10 \mu \mathrm{g} \mu \mathrm{L}^{-1}$. Analytes for the screening of enzyme inhibitors were normally dissolved in water or water/ethanol (1:1) with the concentration of $1.0 \mathrm{mM}$. The solutions of Rhizoma Coptidis dry powders $(4 \mathrm{~g})$ in different kinds of solvents $(50 \mathrm{~mL})$, such as $\mathrm{H}_{2} \mathrm{O}$, aceton, and dimethyl sulfoxide, were refluxed at $110^{\circ} \mathrm{C}$ for $2 \mathrm{~h}$, respectively. The extracted solutions were filtered and evaporated to dryness under a gentle stream of nitrogen and the residue was reconstituted in $\mathrm{H}_{2} \mathrm{O}$.

\section{MALDI-FTMS Conditions}

Experiments were conducted using an Ionspec $4.7 \mathrm{~T}$ HisRes MALDI-FTMS (Ionspec, Irvine, CA, USA). The external Ionspec MALDI ion source used an air-cooled Nd:YAG laser (355 nm, New Wave, Fremont, CA, USA) with a gradient filter for adjusting the UV-laser power. Ions, generated from a MALDI source, were transferred via a quadrupole ion guide to the capacitively coupled closed cylindrical cell. The intensity of MALDI-laser irradiation was varied between $45 \%$ and $50 \%$ as needed. The laser irradiation pulse time was set at $50 \mathrm{~ms}$. For the 
low-mass region, the quadrupole guide had an applied voltage of $30 \mathrm{~V}$ (base to peak) at a frequency of $725 \mathrm{kHz}$. The mass spectrometer was calibrated with PEG-200 and/or PEG-400 for each test. The acquisition mass range was $m / z 80-400$. For the quantitative analysis, the ratio of $\mathrm{ACh}$ to $\mathrm{Ch}$ was acquired by averaging six separate spectra, each obtained from a single laser shot. Two commonly used MALDI matrices, CHCA and DHB, were examined for better ionization efficiency.

The matrix solution was deposited on the stainless steel target to produce a microcrystalline layer of matrix, followed by sample deposition onto the preformed matrix layer. After the sample spots had dried completely, each one was overlaid with $1.0 \mu \mathrm{L}$ of matrix solution, which produced a thin film of homogeneous crystals.

\section{Enzyme Kinetic Assay}

All enzyme assays were carried out in 384-well microtiter plates in an assay volume of $40 \mu \mathrm{L}$ at $37^{\circ} \mathrm{C}$. The reaction mixture of $\mathrm{AChE}$, candidate chemicals (when to determinate the kinetic parameters $K_{\mathrm{m}}$, the candidate chemical solution was replaced by $10 \mathrm{mM}$ Tris- $\mathrm{HCl}$ buffer), and acetylcholine was incubated for $60 \mathrm{~min}$, except if indicated otherwise. Acetonitrile $(30 \mu \mathrm{L})$ was then added to the mixture to quench the reaction. To measure the $K_{\mathrm{m}}$ of the nature substrate $\mathrm{ACh}$, the conversion percentages of acetylcholine $(0.07,0.15,0.33$, 0.37 , and $0.44 \mathrm{mM}$ ) to choline were calculated at different reaction times.

\section{Results and Discussion}

\section{MALDI-FTMS Analysis}

Among the matrices tested (DHB, CHCA, or a mixture of both), DHB gave the best results for the acetylcholine and choline. Figure 1 depicts a typical spectrum obtained by mixing acetylcholine and choline in equal molar ratio. As shown, the signals of substrate $[\mathrm{ACh}]^{+}$ $\left(m / z\right.$ 146.1174) and of product [Ch] ${ }^{+}(\mathrm{m} / \mathrm{z} 104.1071)$ are clearly recognizable, allowing the measurement of low

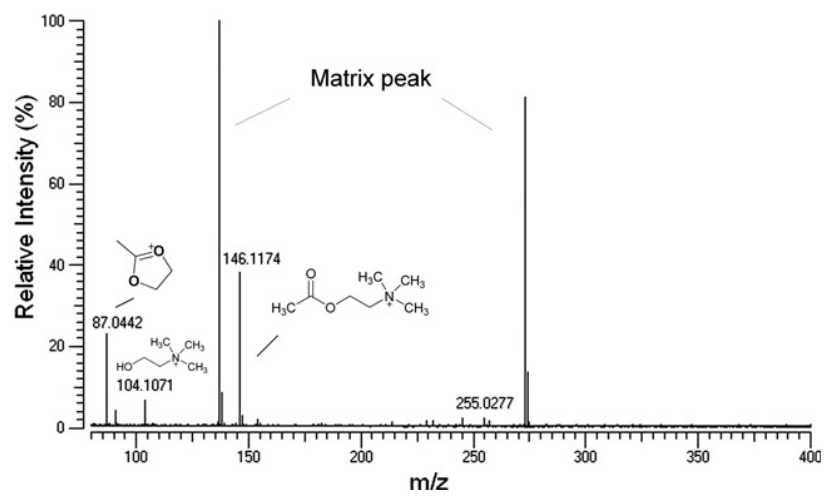

Figure 1. The MALDI-FTMS spectrum obtained for a mixture of acetylcholine $(\mathrm{m} / \mathrm{z} 146)$ and choline $(\mathrm{m} / \mathrm{z} 104)$ in equal molar ratio. molecular mass compounds. The signal of $\mathrm{Ch}$ was detected with a mass resolution of 78,100 , ACh with a mass resolution of 55,300, and the ion of $\mathrm{m} / \mathrm{z} 87$ with a mass resolution of 92,600 . Ions of the compounds of interest were confirmed by the standards, respectively, to eliminate the interference from the candidate chemicals (pure chemical or complex mixture).

As shown in Figure 1, the ion signal of $m / z 87$ was detected, which was thought to result from the fragmentation of acetylcholine $(\mathrm{m} / \mathrm{z} 146)$. The fragmentation pattern observed for the signal $\mathrm{m} / z 146$ under MALDIFTMS (Figure 1) caused by laser energy is in accordance with that observed in ESI-MS/MS. It has been proposed that the structure of the ion $\mathrm{m} / \mathrm{z} 87$ is either a cation $(\mathrm{m} / \mathrm{z}$ 87.0441) [34-37] or a radical cation $(m / z$ 87.1043) [25] (Scheme 2).

By decreasing the laser energy until no signals of $\mathrm{ACh}$ and $\mathrm{Ch}$ are observed, the fragment of $\mathrm{ACh}$ is still observed. The accurate mass measured was 87.0440 [percentage relative standard deviation (\%RSD) = $0.008, n=6$ ], which deviated from the calculated mass of the cation (87.0441) by $1.15 \mathrm{ppm}$, indicating that the product ion $m / z 87$ is a cation. It consists mainly in the elimination of $\mathrm{N}\left(\mathrm{CH}_{3}\right)_{3}$ of $59 \mathrm{u}$, giving the fragment ion of $m / z$ 87. Besides the two structures (Scheme 2, a and b) proposed in previous studies, a five-member cyclic acylium ion (Scheme 2,c) is also possible. B3LYP/6$31 \mathrm{G}(\mathrm{d})$ density functional calculations, as implemented in Gaussian 03 [38], were used to determine the relative energies of the three possible cation structures. The energies listed in Scheme 2 suggested that a would be $173.7 \mathrm{~kJ} / \mathrm{mol}$ higher in energy relative to acylium ion $\mathbf{c}$, and $\mathbf{b}$ would be $81.6 \mathrm{~kJ} / \mathrm{mol}$ higher than $\mathbf{c}$. Thus, the fragmentation of ACh is more likely to form the cation c, which is more favorable in energy.

\section{Calibration and Quantification by MALDI-FTMS}

In the presence of acetylcholinesterase, acetylcholine is completely converted to choline, corresponding to a change in molecular mass from 146 to 104 . The presence of AChE does not interfere with the detection of any of the small molecules of interest. Relative peak-height ratios of product to substrate determined by MALDIFTMS allow the quantitative analysis of enzymatic reaction for screening purposes. Usually six to eight positions from one sample spot were used for the average. As shown in Scheme 2, the fragmentation of ACh could produce the ion signal of $m / z$ 87. It was necessary to find a proper ion signal to indicate the amount of ACh from the mass spectrum. Thus, three different ion signals $(m / z 87, m / z 146$, and the sum of both) were investigated. Relative intensities of $[\mathrm{Ch}]^{+}$to $\left[\mathrm{ACh}-\mathrm{N}\left(\mathrm{CH}_{3}\right)_{3}\right]^{+},[\mathrm{ACh}]^{+}$and $\sum\left(\left[\mathrm{ACh}-\mathrm{N}\left(\mathrm{CH}_{3}\right)_{3}\right]^{+}\right.$, $\left.[\mathrm{ACh}]^{+}\right)$, respectively, were obtained for the calibration curve of product (Figure 2). Calibration curves were established by plotting the intensity ratios against the choline concentration in the sample solution (0.02-311 mmol L ${ }^{-1}$ ). The concentration of the acetylcholine (in- 


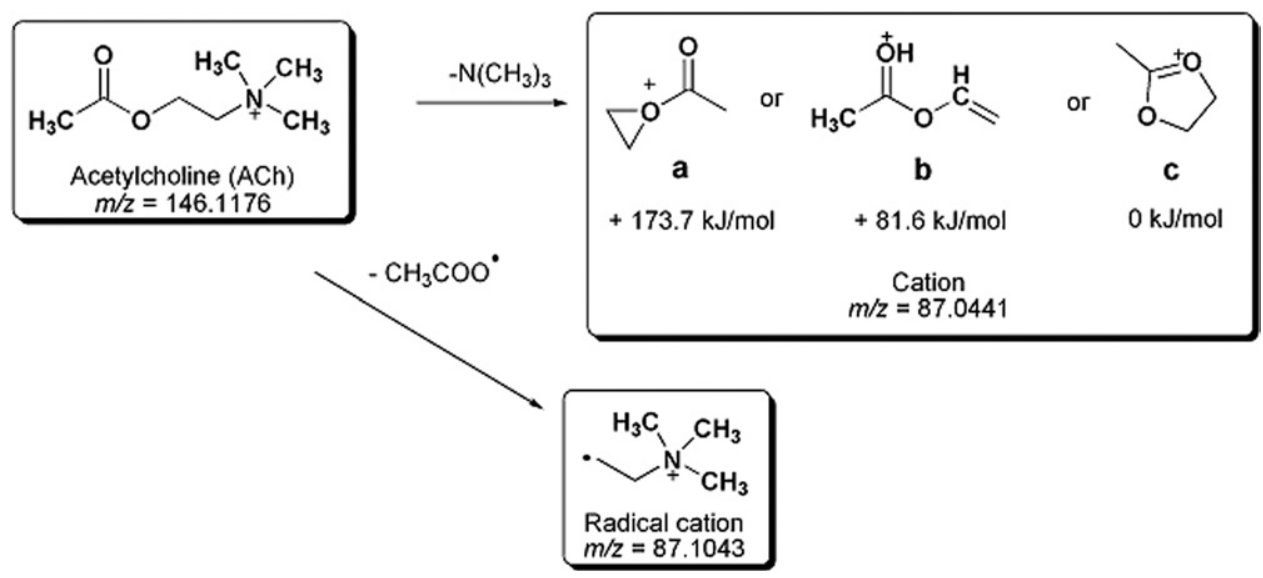

Scheme 2. Different conceivable fragmentation patterns for acetylcholine in MALDI-FTMS. The energies listed below the structures of three possible cations are based on the B3LYP/6-31G(d) density functional calculations.

ternal standard) was $3.89 \mathrm{mmol} \mathrm{L}^{-1}$. From the resulting calibration curve the regression coefficient, $y$-intercept and slope were calculated, characterizing the calibration function.

The data points of curve a in Figure 2 showed large error bars and poor correlation coefficient $(r=0.9897)$, compared with curves $\mathrm{b}$ and $\mathrm{c}$. The calibration curve (Figure 2c) by plotting the intensity ratio of $[\mathrm{Ch}]^{+}$to $\sum\left(\left[\mathrm{ACh}-\mathrm{N}\left(\mathrm{CH}_{3}\right)_{3}\right]^{+},[\mathrm{ACh}]^{+}\right)$against the concentra-

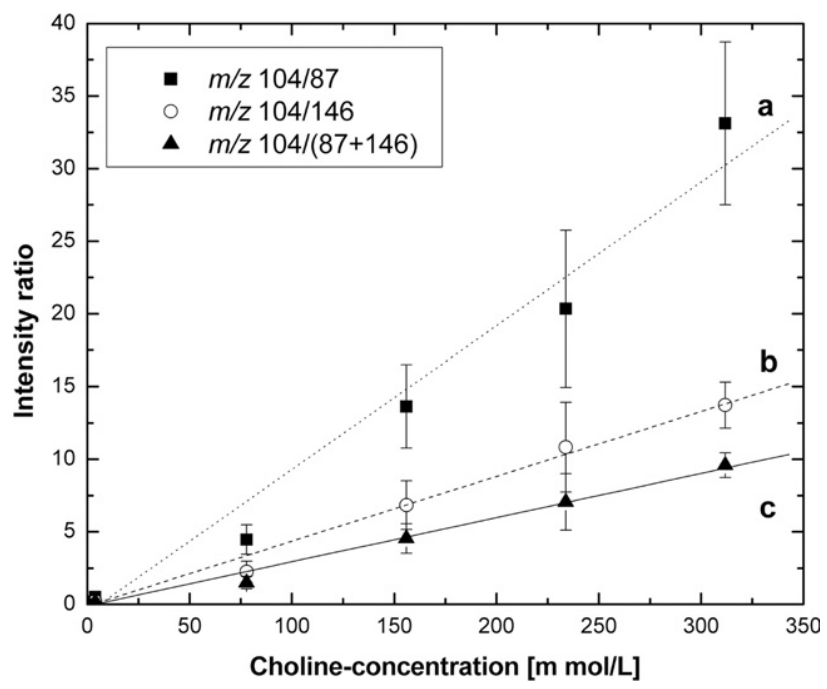

Figure 2. Calibration curves of intensity ratio versus the concentration of choline established for three different relative intensities (the fragment of acetylcholine, acetylcholine, or both of them). From the calibration curve, $\mathrm{X}$ means the concentration of choline: (a) $\mathrm{Y}$ means the relative intensity of $[\mathrm{Ch}]^{+}$to $\left[\mathrm{ACh}-\mathrm{N}\left(\mathrm{CH}_{3}\right)_{3}\right]^{+}$, $\mathrm{Y}=-0.5984+0.0989 \mathrm{X}, r=0.9897$; (b) $\mathrm{Y}$ means the relative intensity of $[\mathrm{Ch}]^{+}$to $[\mathrm{ACh}]^{+}, \mathrm{Y}=-0.1306+0.0448 \mathrm{X}, r=0.9966$; (c) $\mathrm{Y}$ means the relative intensity of $[\mathrm{Ch}]{ }^{+}$to $\sum([\mathrm{ACh}-$ $\left.\left.\mathrm{N}\left(\mathrm{CH}_{3}\right)_{3}\right]^{+},[\mathrm{ACh}]^{+}\right), \mathrm{Y}=-0.1145+0.0305 \mathrm{X}, r=0.9966$. Calibration curves were established by plotting the intensity ratios against the choline concentration in the sample solution (0.02-311 $\mathrm{mmol} \mathrm{L} \mathrm{L}^{-1}$ ). The concentration of the acetylcholine (internal standard) was $3.89 \mathrm{mmol} \mathrm{L}^{-1}$. The data points displayed represent the mean for six replicate measurements. tion of choline was linear over five orders of magnitude, ranging from 0.02 to $311 \mathrm{mmol} \mathrm{L}^{-1}$ of choline, with a correlation coefficient of 0.9966 . This result showed high accuracy and good reproducibility. The relative intensity of $[\mathrm{Ch}]^{+}$to $[\mathrm{ACh}]^{+}$(Figure $2 \mathrm{~b}$ ) also gave reliable calibration curves $(r=0.9966)$, although with a worse reproducibility. So, the intensities ratio of [Ch] to $\sum\left(\left[\mathrm{ACh}-\mathrm{N}\left(\mathrm{CH}_{3}\right)_{3}\right]^{+},[\mathrm{ACh}]^{+}\right)$(Figure 2c) is used to quantitative detection of choline in the following section.

The limits of detection and quantification (LOD and LOQ, respectively) were determined by analyzing a series of standard solutions until the signal-to-noise $(\mathrm{S} / \mathrm{N})$ ratio for each compound was around 3 for LOD and 10 for LOQ. LOD for the MALDI-FTMS analysis was determined as 2.44 picomolar (pM) for acetylcholine and $6.09 \mathrm{pM}$ for choline. LOQ was 9.74 and 19.77 $\mathrm{pM}$ for acetylcholine and choline, respectively.

\section{Determination of the Michaelis Constant $\left(K_{m}\right)$ for Acetylcholinesterase}

Enzyme reaction was monitored by MALDI-FTMS analysis. It was possible to follow the reaction over time by monitoring the decrease of signal intensity of acetylcholine and the increase of that of choline (Figure 3). According to the calibration curve constructed earlier, the conversion percentages of acetylcholine to choline were calculated at different reaction times. Under the conditions used in this study, the conversion of acetylcholine is roughly $55 \%$ after $40 \mathrm{~min}$ of reaction. To increase the screening throughput, a high-concentration solution of acetylcholinesterase $\left(1.4 \mu \mathrm{mol} \mathrm{L}{ }^{-1}\right)$ could be used for the following experiments. In this case, AChE could completely transform $\mathrm{ACh}$ to $\mathrm{Ch}$ in $1 \mathrm{~h}$.

Initial velocities of enzymatic reaction are measured by change in product $\mathrm{Ch}$ amounts with time at the linear region of the process curve. The average reaction velocity within the first $20 \mathrm{~min}$ was considered as the 


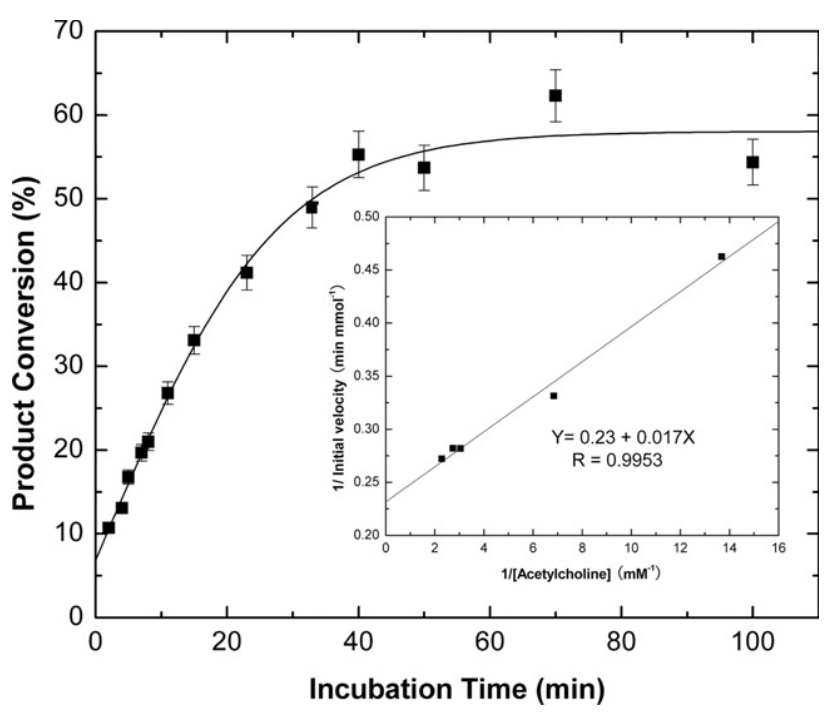

Figure 3. Process curve of choline formation as a function of incubation time. The initial substrate concentration was $1.4 \mathrm{nmol}$ $\mathrm{L}^{-1}$. Inset: Lineweaver-Burk plot of acetylcholinesterase. The concentration of acetylcholine was varied from 0.07 to $0.48 \mathrm{mmol}$ $\mathrm{L}^{-1}$ and the concentration of acetylcholinesterase was kept at 1.4 $\mu \mathrm{mol} \mathrm{L}{ }^{-1}$. From Lineweaver-Burk plot, $K_{\mathrm{m}}=$ slope/intercept. The reaction was performed at $37^{\circ} \mathrm{C}$.

initial velocity of the reaction (five time points per sample). To determine $K_{\mathrm{m}}$, the reaction must be run using a range of substrate concentrations (from 0.07 to $0.44 \mathrm{mM}$ ). The initial velocity of the reaction is then determined for each concentration. A plot of 1 /[initial velocity] versus $1 /[\mathrm{ACh}]$ generates a Lineweaver-Burk plot and a linear regression fit to this data is then used to estimate the $K_{\mathrm{m}}\left(K_{\mathrm{m}}=\right.$ slope/intercept $)$. The good linearity of the Lineweaver-Burk plot for acetylcholine shown in Figure 3 (inset) demonstrates the accuracy of steady-state kinetics in this assay. The Michaelis constant $\left(K_{\mathrm{m}}\right)$ is defined as the substrate concentration at which the reaction occurs at half of the maximum velocity, with a value typically in the range of $10^{-1}$ $10^{-5} \mathrm{~mol} \mathrm{~L}^{-1}$ [39]. The $K_{\mathrm{m}}$ of acetylcholinesterase was determined to be $73.9 \mu \mathrm{mol} \mathrm{L} \mathrm{L}^{-1}$. Values obtained using the MALDI-FTMS-based assay are well within the range of values reported in other studies ( $43 \mu \mathrm{M}$ [40], 61 $\mu \mathrm{M}$ [41], $98 \mu \mathrm{M}$ [31], $0.23 \mathrm{mM}$ [33], respectively).

\section{Inhibition Kinetics}

The screening of potential AChE inhibitors was performed by monitoring the conversion ratio of $\mathrm{ACh}$ in the presence of candidate compounds. Three commercially available AChE inhibitors-Reminyl (galantamine hydrobromide), Excelon (rivastigmine tartrate), and Huperzine A-were used to evaluate the methodology individually. In the absence of inhibitor, the reaction catalyzed by $\mathrm{AChE}$ could reach completion within $60 \mathrm{~min}$. While the active compound was added to the reaction system, $\mathrm{AChE}$ could not catalyze the complete transformation of $\mathrm{ACh}$ into $\mathrm{Ch}$ in $1 \mathrm{~h}$. The remaining $\mathrm{ACh}$ indicates the inhibition potency of the compound. All three of them showed inhibitory effects on the activity of AChE (Figure 4a). To test whether the system was effective in a real screening
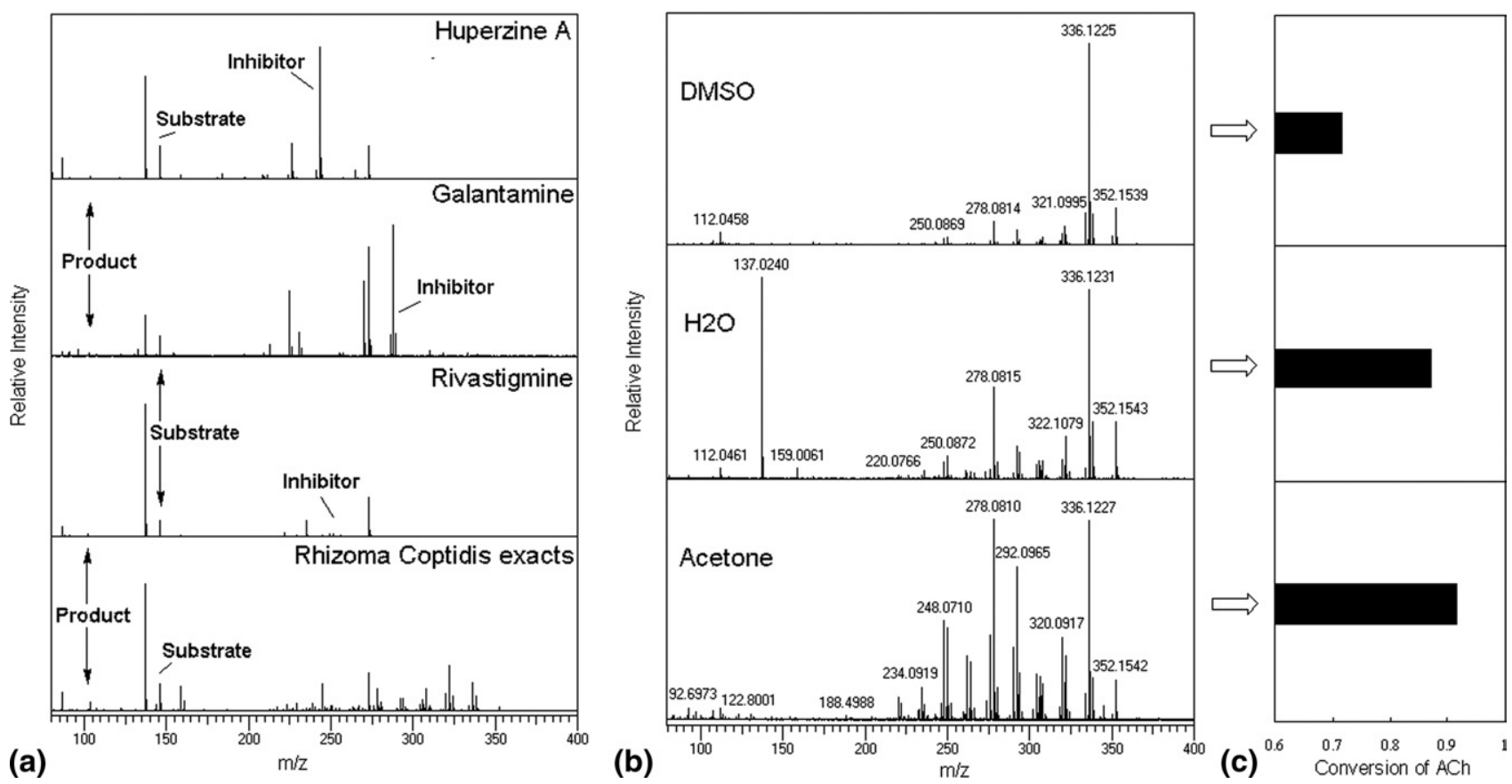

Figure 4. (a) The mass spectra for screening of inhibitors, including three commercially available drugs and Rhizoma Coptidis extracts. (b) The mass spectra of crude Rhizoma Coptidis extracts using different solvents (top, DMSO; middle, $\mathrm{H}_{2} \mathrm{O}$; bottom, acetone). (c) Conversion of ACh in the presence of three Rhizoma Coptidis extracts, respectively (top, DMSO; middle, $\mathrm{H}_{2} \mathrm{O}$; bottom, acetone). 
experiment, an extract was made from Rhizoma Coptidis, which is a commonly used herb in Chinese medicine. Berberine, the representative quaternary ammonium alkaloid in commercial Rhizoma Coptidis, is an AChE inhibitor [42]. Three solvents were used to extract the active components from the dry powders of Rhizoma Coptidis. As expected, Rhizoma Coptidis extracts inhibited the activity of acetylcholinesterase by the present method (Figure 4 a). By monitoring the conversion percentage of $\mathrm{ACh}$, the inhibitory activity of a candidate compound can be determined. Low conversion of ACh indicates the candidate compound shows relative high inhibitory activity against AChE. As revealed in Figure $4 b$, compared to water and acetone,
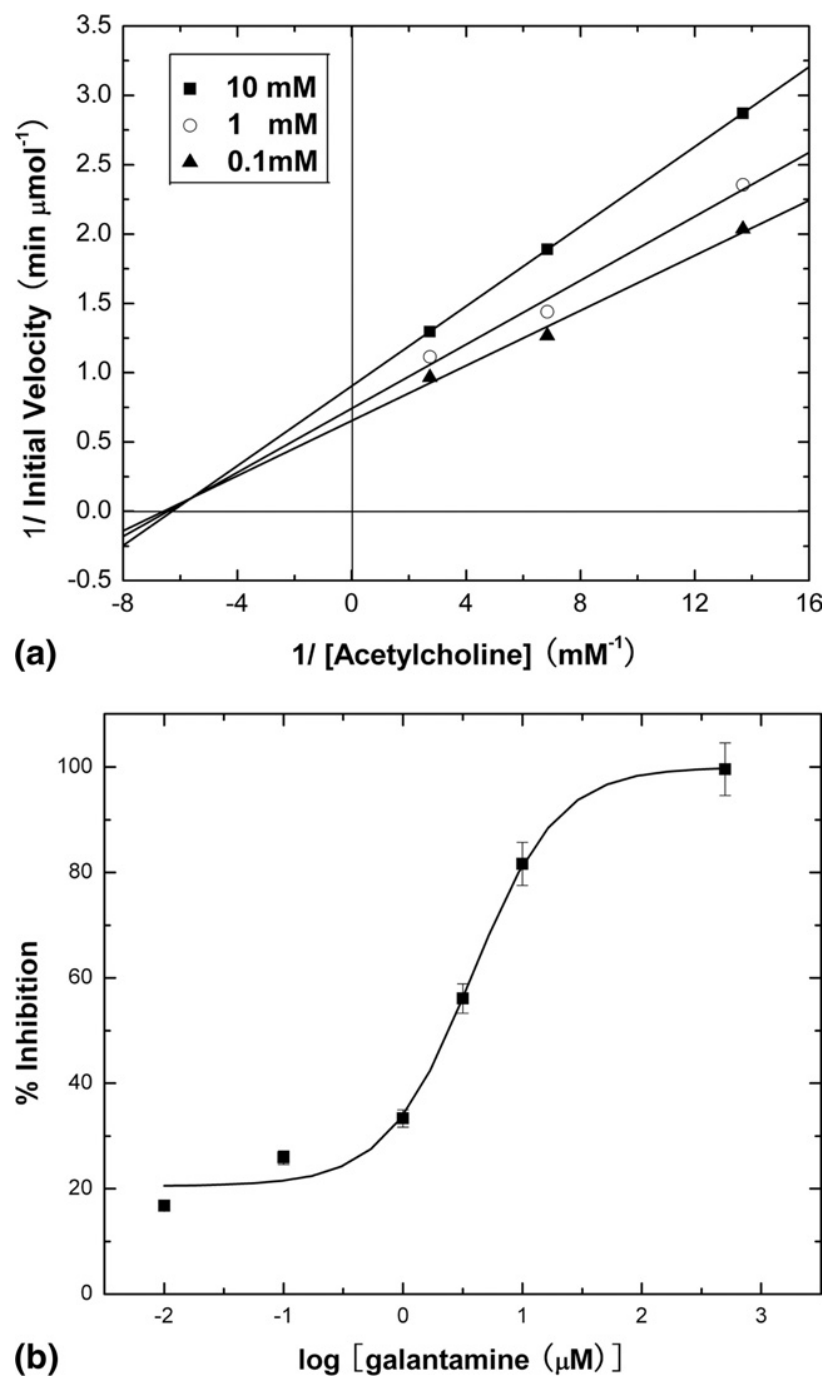

Figure 5. (a) Lineweaver-Burk plots for Huperzine A. The concentration of acetylcholine was varied from 0.07 to $0.48 \mathrm{mM}$ and the concentration of inhibitor Huperzine A was varied from 0.1 to $10 \mathrm{mM}$ in $\log$ dilutions $\left(-\boldsymbol{-}-, 10 \mathrm{mM} ;-\bigcirc-, 1 \mathrm{mM} ;-\boldsymbol{\Delta}_{-}, 0.1 \mathrm{mM}\right)$. -匹-: $\mathrm{Y}=0.9028+0.1439 \mathrm{X}, r=0.9999 ;-\mathrm{O}-\mathrm{Y}=0.7418+0.1154 \mathrm{X}$, $r=0.9924 ;-\boldsymbol{\Delta}_{-}: \mathrm{Y}=0.6531+0.0993 \mathrm{X}, r=0.9945$. (b) Inhibition plot of galantamine. The $\mathrm{IC}_{50}$ value displayed represents the mean for six replicate measurements. The concentration of acetylcholine was $0.7 \mathrm{mmol} \mathrm{L}^{-1}$ and the concentration of acetylcholinesterase was kept at $1.4 \mu \mathrm{mol} \mathrm{L}^{-1}$. The reactions were performed at $37^{\circ} \mathrm{C}$. berberine $(m / z$ 336.1230) was more selectively extracted using DMSO as solvent. In this case, the activity of AChE was more significantly decreased. We can conclude that, depending on how the Rhizoma Coptidis dry powders are extracted, because of the different properties of solvents, the amount of effective components can be altered, as well as the conversion efficiency of ACh to $\mathrm{Ch}$ in the presence of AChE (Figure 4c).

The Lineweaver-Burk plots obtained at different inhibitor concentrations for Huperzine A are shown in Figure 5. The resulting plots showed that Huperzine A displayed a mixed inhibition, with competitive and noncompetitive inhibition behaviors. The obtained data in our experiment are in accordance with the literature [43]. The inhibition plot of galantamine is shown in Figure $5 \mathrm{~b}$. The $\mathrm{IC}_{50}$ value of galantamine was determined as $2.39 \mu \mathrm{M}$, which was comparable with the literature values of 0.42 to $5 \mu \mathrm{M}(0.42 \mu \mathrm{M}$ for Torpedo californica AChE [44], $0.61 \mu \mathrm{M}$ for Electrophorus electricus AChE [44], $5 \mu \mathrm{M}$ for AChE in postmortem brain tissue from AD patients [45]).

\section{Conclusions}

In this study, a MALDI-FTMS method for monitoring enzyme reaction and screening of inhibitor against acetylcholinesterase has been developed. MALDIFTMS can be easily and simply applied to study steadystate kinetics for an acetylcholinesterase system. Compared with other methods, the matrix used in this report is simpler and easier to acquire. The extract mass and high-resolution measurements by using FTMS as detection system make it possible to extend this methodology to complex mixtures and biological samples. The small cost of the materials and a short time of scanning required make this method an optimal choice for high-throughput screening of inhibitors from a library of compounds. We assume that this method might be useful for other types of enzymes.

\section{Acknowledgments}

This work was supported by the National Natural Science Foundation of China (No. 20632070) and Chinese Academy of Sciences (KGCX3-SYW-203-03). The authors also acknowledge Prof. Xingxiang $\mathrm{Xu}$ at Shanghai Institute of Organic Chemistry for providing us with the rivastigmine tartrate.

\section{References}

1. Copeland, R. A. Evaluation of Enzyme Inhibitors in Drug Discovery: A Guide for Medicinal Chemists and Pharmacologists, Wiley Interscience: Hoboken, NJ, 2005; p 296.

2. Imming, P.; Sinning, C.; Meyer, A. Drugs, Their Targets and the Nature and Number of Drug Targets. Nat. Rev. Drug Disc. 2006, 5, 821-834.

3. Noble, M. E. M.; Endicott, J. A.; Johnson, L. N. Protein Kinase Inhibitors: Insights into Drug Design from Structure. Science 2004, 303, 1800-1805.

4. Gros, C.; Noel, N.; Souque, A.; Schwartz, J.; Danvy, D.; Plaquevent, J.; Duhamel, L.; Duhamel, P.; Lecomte, J.; Bralet, J. Mixed Inhibitors of Angiotensin-Converting Enzyme (EC 3.4.15.1) and Enkephalinase (EC 3.4.24.11): Rational Design, Properties, and Potential Cardiovascular Applications of Glycopril and Alatriopril. Proc. Natl. Acad. Sci. U. S. A. 1991, 88, 4210-4214. 
5. von Ahsen, O.; Bomer, U. High-Throughput Screening for Kinase Inhibitors. ChemBioChem 2005, 6, 481-490.

6. Costagli, C.; Galli, A. Inhibition of Cholinesterase-associated Aryl Acylamidase Activity by Anticholinesterase Agents: Focus on Drugs Potentially Effective in Alzheimer's Disease. Biochem. Pharmacol. 1998, $55,1733-1737$

7. Salehi, A.; Delcroix, J. D.; Swaab, D. F. Alzheimer's Disease and NGF Signaling. J. Neural Transm. 2004, 111, 323-345.

8. Bartolini, M.; Andrisano, V.; Wainer, I. W. Development and Characterization of an Immobilized Enzyme Reactor Based on Glyceraldehyde-3phosphate Dehydrogenase for On-line Enzymatic Studies. J. Chromatogr. A 2003, 987, 331-340.

9. Hemmila, I. A.; Hurskainen, P. Novel Detection Strategies for Drug Discovery. Drug Discov. Today 2002, 7, S150-S156.

10. Fujii, T.; Harada, H.; Koyama, T.; Nakajima, Y.; Kawashima, K. Effects of Physostigmine and Calcium on Acetylcholine Efflux from the Hippocampus of Freely Moving Rats as Determined by In Vivo Microdialysis and a Radioimmunoassay. Neurosci. Lett. 2000, 289, 181-184.

11. Ellman, G. L.; Courtney, K. D.; Andres, V.; Featherstone, R. M. A New and Rapid Colorimetric Determination of Acetylcholinesterase Activity. Biochem. Pharmacol. 1961, 7, 88-90.

12. Ozbal, C. C.; LaMarr, W. A.; Linton, J. R.; Green, D. F.; Katz, A.; Morrison, T. B.; Brenan, C. J. H. High Throughput Screening via Mass Spectrometry: A Case Study Using Acetylcholinesterase. Assay Drug Dev. Technol. 2004, 2, 373-381.

13. Bothner, B.; Chavez, R.; Wei, J.; Strupp, C.; Phung, Q.; Schneemann, A.; Siuzdak, G. Monitoring Enzyme Catalysis with Mass Spectrometry. J. Biol. Chem. 2000, 275, 13455-13459.

14. Houston, C. T.; Taylor, W. P.; Widlanski, T. S.; Reilly, J. P. Investigation of Enzyme Kinetics Using Quench-Flow Techniques with MALDI-TOF Mass Spectrometry. Anal. Chem. 2000, 72, 3311-3319.

15. Liesener, A.; Karst, U. Monitoring Enzymatic Conversions by Mass Spectrometry: A Critical Review. Anal. Bioanal. Chem. 2005, 382, 14511464.

16. de Boer, A. R.; Lingeman, H.; Niessen, W. M. A.; Irth, H. Mass Spectrometry-Based Biochemical Assays for Enzyme Inhibitor Screening. Trac-Trend. Anal. Chem. 2007, 26, 867-883.

17. Cancilla, M. T.; Leavell, M. D.; Chow, J.; Leary, J. A. Mass Spectrometry and Immobilized Enzymes for the Screening of Inhibitor Libraries. Proc. Natl. Acad. Sci. U. S. A. 2000, 97, 12008

18. Ge, X.; Sirich, T. L.; Beyer, M. K.; Desaire, H.; Leary, J. A. A Strategy for the Determination of Enzyme Kinetics Using Electrospray Ionization with an Ion Trap Mass Spectrometer. Anal. Chem. 2001, 73, 5078-5082.

19. Verdugo, D. E.; Cancilla, M. T.; Ge, X.; Gray, N. S.; Chang, Y. T.; Schultz, P. G.; Negishi, M.; Leary, J. A.; Bertozzi, C. R. Discovery of Estrogen Sulfotransferase Inhibitors from a Purine Library Screen. J. Med. Chem. 2001, 44, 2683-2686.

20. Pi, N.; Armstrong, J. I.; Bertozzi, C. R.; Leary, J. A. Kinetic Analysis of NodST Sulfotransferase Using an Electrospray Ionization Mass Spectrometry Assay. Biochemistry 2002, 41, 13283-13288.

21. Gao, H.; Leary, J. A. Multiplex Inhibitor Screening and Kinetic Constant Determinations for Yeast Hexokinase Using Mass Spectrometry Based Assays. J. Am. Soc. Mass Spectrom. 2003, 14, 173-181.

22. Attwood, P. V.; Geeves, M. A. Kinetics of an Enzyme-Catalyzed Reaction Measured by Electrospray Ionization Mass Spectrometry Using a Simple Rapid Mixing Attachment. Anal. Biochem. 2004, 334, 382-389.

23. Dennhart, N.; Letzel, T. Mass Spectrometric Real-Time Monitoring of Enzymatic Glycosidic Hydrolysis, Enzymatic Inhibition and Enzyme Complexes. Anal. Bioanal. Chem. 2006, 386, 689-698.

24. de Jong, C. F.; Derks, R. J. E.; Bruyneel, B.; Niessen, W.; Irth, H. High-Performance Liquid Chromatography-Mass Spectrometry-Based Acetylcholinesterase Assay for the Screening of Inhibitors in Natural Extracts. J. Chromatogr. A 2006, 1112, 303-310.

25. Hows, M. E. P.; Organ, A. J.; Murray, S.; Dawson, L. A.; Foxton, R.; Heidbreder, C.; Hughes, Z. A.; Lacroix, L.; Shah, A. J. High-Performance Liquid Chromatography/Tandem Mass Spectrometry Assay for the Rapid High Sensitivity Measurement of Basal Acetylcholine from Microdialysates. J. Neurosci. Methods 2002, 121, 33-39.

26. Shih, T.-M.; Scremin, O.; Roch, M.; Huynh, L.; Sun, W.; Jenden, D. Cerebral Acetylcholine and Choline Contents and Turnover Following Low-Dose Acetylcholinesterase Inhibitors Treatment in Rats. Arch. Toxicol. 2006, 80, 761-767.

27. Schriemer, D. C.; Bundle, D. R.; Li, L.; Hindsgaul, O. Micro-Scale Frontal Affinity Chromatography with Mass Spectrometric Detection: A New Method for the Screening of Compound Libraries. Angew. Chem. Int. Ed. 1998, 37, 3383-3387.

28. Lyubarskaya, Y. V.; Carr, S. A.; Dunnington, D.; Prichett, W. P.; Fisher, S. M.; Appelbaum, E. R.; Jones, C. S.; Karger, B. L. Screening for
High-Affinity Ligands to the Src SH2 Domain Using Capillary Isoelectric Focusing-Electrospray Ionization Ion Trap Mass Spectrometry. Anal. Chem. 1998, 70, 4761-4770.

29. Markgren, P. O.; Hamalainen, M.; Danielson, U. H. Kinetic Analysis of the Interaction between HIV-1 Protease and Inhibitors Using Optical Biosensor Technology. Anal. Biochem. 2000, 279, 71-78.

30. Tang, Z. M.; Kang, J. W. Enzyme Inhibitor Screening by Capillary Electrophoresis with an On-column Immobilized Enzyme Microreactor Created by an Ionic Binding Technique. Anal. Chem. 2006, 78, 25142520

31. Wall, D. B.; Finch, J. W.; Cohen, S. A. Comparison of Desorption/ Ionization on Silicon (DIOS) Time-of-Flight and Liquid Chromatography/ Tandem Mass Spectrometry for Assaying Enzyme-Inhibition Reactions. Rapid Commun. Mass Spectrom. 2004, 18, 1482-1486.

32. Thomas, J. J.; Shen, Z.; Crowell, J. E.; Finn, M. G.; Siuzdak, G. Desorption/ionization on silicon (DIOS): A Diverse Mass Spectrometry Platform for Protein Characterization. Proc. Natl. Acad. Sci. U. S. A. 2001, $98,4932-4937$.

33. Hu, L.; Jiang, G.; Xu, S.; Pan, C.; Zou, H. Monitoring Enzyme Reaction and Screening Enzyme Inhibitor Based on MALDI-TOF-MS Platform with a Matrix of Oxidized Carbon Nanotubes. J. Am. Soc. Mass Spectrom. 2006, 17, 1616-1619.

34. Uutela, P.; Reinila, R.; Piepponen, P.; Ketola, R. A.; Kostiainen, R. Analysis of Acetylcholine and Choline in Microdialysis Samples by Liquid Chromatography/Tandem Mass Spectrometry. Rapid Commun Mass Spectrom. 2005, 19, 2950-2956.

35. Keski-Rahkonen, P.; Lehtonen, M.; Thalainen, J.; Sarajarvi, T; Auriola, S. Quantitative Determination of Acetylcholine in Microdialysis Samples Using Liquid Chromatography/Atmospheric Pressure Spray Ionization Mass Spectrometry. Rapid Commun. Mass Spectrom. 2007, 21, 2933-2943.

36. Zhang, M.-Y.; Hughes, Z. A.; Kerns, E. H.; Lin, Q.; Beyer, C. E. Development of a Liquid Chromatography/Tandem Mass Spectrometry Method for the Quantitation of Acetylcholine and Related Neurotransmitters in Brain Microdialysis Samples. J. Pharm. Biomed. 2007, 44, 586-593.

37. Dunphy, R.; Burinsky, D. J. Detection of Choline and Acetylcholine in a Pharmaceutical Preparation Using High-Performance Liquid Chromatography/Electrospray Ionization Mass Spectrometry. J. Pharm. Biomed. 2003, 31, 905-915.

38. Frisch, M.; Trucks, G.; Schlegel, H.; Scuseria, G.; Robb, M.; Cheeseman J.; Montgomery, J.; Vreven, T.; Kudin, K.; Burant, J.; Millam, J.; Iyengar, S.; Tomasi, J.; Barone, V.; Mennucci, B.; Cossi, M.; Scalmani, G.; Rega, N.; Petersson, G.; Nakatsuji, H.; Hada, M.; Ehara, M.; Toyota, K. Fukuda, R.; Hasegawa, J.; Ishida, M.; Nakajima, T.; Honda, Y.; Kitao, O.; Nakai, H.; Klene, M.; Li, X.; Knox, J.; Hratchian, H.; Cross, J.; Adamo, C.; Jaramillo, J.; Gomperts, R.; Stratmann, R.; Yazyev, O.; Austin, A.; Cammi, R.; Pomelli, C.; Ochterski, J.; Ayala, P.; Morokuma, K.; Voth, G.; Salvador, P.; Dannenberg, J.; Zakrzewski, V.; Dapprich, S.; Daniels, A. Strain, M.; Farkas, O.; Malick, D.; Rabuck, A.; Raghavachari, K.; Foresman, J.; Ortiz, J.; Cui, Q.; Baboul, A.; Clifford, S.; Cioslowski, J.; Stefanov, B.; Liu, G.; Liashenko, A.; Piskorz, P.; Komaromi, I.; Martin, R.; Fox, D.; Keith, T.; Al-Laham, M.; Peng, C.; Nanayakkara, A.; Challacombe, M.; Gill, P.; Johnson, B.; Chen, W.; Wong, M.; Gonzalez, C.; Pople, J. Gaussian 03, Revision B. 01; Gaussian, Inc: Pittsburgh, PA, 2003.

39. Taylor, K. B. Enzyme Kinetics and Mechanisms, Kluwer Academic Publishers: Dordrecht, The Netherlands, 2002; p 244.

40. De Jaco, A.; Comoletti, D.; Kovarik, Z.; Gaietta, G.; Radic, Z.; Lockridge, O.; Ellisman, M. H.; Taylor, P. A Mutation Linked with Autism Reveals a Common Mechanism of Endoplasmic Reticulum Retention for the \{alpha\},beta-Hydrolase Fold Protein Family. J. Biol. Chem. 2006, 281, 9667-9676.

41. Al-Jafari, A. A.; Kamal, M. A.; Alhomida, A. S. Sensitivity of Bovine Retinal Acetylcholinesterase (E.C. 3.1.1.7) Toward Tacrine: Kinetic Characterization. J. Biochem. Mol. Toxicol. 1998, 12, 245-251.

42. Houghton, P. J.; Howes, M. J. Natural Products and Derivatives Affecting Neurotransmission Relevant to Alzheimer's and Parkinson's Disease. Neurosignals 2005, 14, 6-22.

43. Hogenauer, K.; Baumann, K.; Enz, A.; Mulzer, J. Synthesis and Acetylcholinesterase Inhibition of 5-Desamino Huperzine A Derivatives Bioorg. Med. Chem. Lett. 2001, 11, 2627-2630.

44. Greenblatt, H. M. Guillou, C.; Guenard, D; Argaman, A.; Botti, S. Badet, B.; Thal, C.; Silman, I.; Sussman, J. L. The Complex of a Bivalent Derivative of Galanthamine with Torpedo Acetylcholinesterase Displays Drastic Deformation of the Active-Site Gorge: Implications for Structure-Based Drug Design. J. Am. Chem. Soc. 2004, 126, 15405-15411.

45. Rakonczay, Z. Potencies and Selectivities of Inhibitors of Acetylcholinesterase and Its Molecular Forms in Normal and Alzheimer's Disease Brain. Acta. Biol. Hung. 2003, 54, 183-189. 